\title{
Ermete: A Decision Support System for an Innovative Management of Knowledge and Prescription in Laboratory Medicine: A Trial of Two Italian Local Health Authorities
}

\author{
Alessandro Camerotto ${ }^{1}$, Vincenza Truppo ${ }^{1}$, Alessia Pozzato $^{2}$, Simone Bedendo $^{1}$, Gabriele Angiolelli $^{3}$, \\ Arianna Lucchiari ${ }^{1}$, Massimo Tosini ${ }^{4}$, Alessandra Saggin ${ }^{5}$, Francesco Noce ${ }^{6}$, Stefano Rigo $^{7}$, \\ Alessio Gasparetto ${ }^{8}$, Roberto Mencarelli ${ }^{1}$ \\ ${ }^{1}$ Department of Clinical Pathology, Local Health Authority, Rovigo, Italy \\ ${ }^{2}$ Department of Obstetrics and Gynecology, Local Health Authority, Rovigo, Italy \\ ${ }^{3}$ Health and Social Care, Local Health Authority, Mirano, Italy \\ ${ }^{4}$ Italian Association of Public Health Sociology, Ferrara, Italy \\ ${ }^{5}$ SDA- Bocconi School of Management, Milan, Italy \\ ${ }^{6}$ General Practice, Local Health Authority, Rovigo, Italy \\ ${ }^{7}$ Department of General Medicine, Local Health Authority, Mirano, Italy \\ ${ }^{8}$ Information Technology, Local Health Authority, Rovigo, Italy
}

\section{Email address:}

alessandro.camerotto@aulss5.veneto.it (A. Camerotto)

\section{To cite this article:}

Alessandro Camerotto, Vincenza Truppo, Alessia Pozzato, Simone Bedendo, Gabriele Angiolelli, Arianna Lucchiari, Massimo Tosini, Alessandra Saggin, Francesco Noce, Stefano Rigo, Alessio Gasparetto, Roberto Mencarelli. Ermete: A Decision Support System for an Innovative Management of Knowledge and Prescription in Laboratory Medicine: A Trial of Two Italian Local Health Authorities. American Journal of Clinical and Experimental Medicine. Vol. 5, No. 4, 2017, pp. 115-122. doi: 10.11648/j.ajcem.20170504.13

Received: May 24, 2017; Accepted: June 9, 2017; Published: June 22, 2017

\begin{abstract}
Laboratory tests play an important role in the diagnostic process. Unfortunately, their utility is at present affected by a significant rate of inappropriate prescriptions. The current strategies to solve the problem are not adequate. The aim of this study is to propose a structural solution through the Health Information Technology. Between the years 2008 and 2010 , a methodology to prescribe laboratory tests with the aid of a Decision Support System (DSS), denomened Ermete, has been tested in collaboration with General Practitioners of Local Health Authorities of Rovigo and Mirano. The DSS, during the process of prescription, showed indications of appropriateness in real time and the general practitioner might or might not accept the indication. The number of prescriptions processed with DSS was compared with the number of prescriptions issued by the same physicians, in the same period of the previous year, without the assistance of the DSS. Results showed a decrease of the total number of prescriptions when the DSS was used. The reduction rate was 37.2\% in Rovigo and $26.1 \%$ in Mirano. The achieved results showed that it is possible to perform the governance of prescriptions without political and administrative actions. The DSS was effective in reducing inappropriateness and in managing knowledge.
\end{abstract}

Keywords: Decision Support System, Inappropriateness, Health Information Technology, Knowledge Management

\section{Introduction}

Diagnosis $(\delta 1 \alpha-\gamma v 0 \sigma 1 \sigma$ from ancient Greek: " $\delta 1 \alpha$ " through

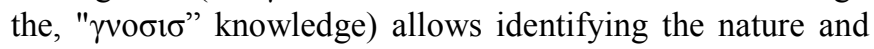
location of a disease through the awareness of symptoms and signs. A diagnosis should be the result produced by listening, observing and studying the patient. This process utilizes devices such as history and semiotics, which are flanked by laboratory tests that, as other techniques such as medical imaging, can be considered the technological extension of the senses of the physician. Knowledge is the faculty that allows conscious decisions within the diagnostic process and that leads the subsequent actions on the patient $[1,2]$. Laboratory 
tests have taken a leading role as diagnostic decision aids, having been estimated that the Laboratory Medicine influences $60-70 \%$ the diagnosis [3]. This leading role is confirmed, for example, by the data of the Veneto Region (about 5 million inhabitants), showing that in public health structures more than 70 million tests/year, for a value of about 322 million euros, are carried out [2]. The budget of Laboratory Medicine in Italy is only $2 \%$ of the total health care cost, which is anyway relevant. On the other hand, the utility of diagnostic tests is affected by a significant proportion of inappropriateness [5]. A literature estimates the phenomenon of over-and underutilization between $10-50 \%$ of the total demand [6-21].

Despite the difficulty to evaluate objectively the appropriateness [22], the feeling of its relevance among professionals is, in any case, widespread, especially with regard to the excessive demand, even if there are data that prove an underestimation of the potentialities of the laboratory [23]. The source of the problem may essentially come from three causes: a) the low cost of laboratory tests (account as "little ticket technologies") could lead physicians to think that these benefits cannot be denied to the patient. This fact together with the facility of access (usually without reservation and waiting times), may contribute to make the laboratory performance too easily available; b) defensive medicine may persuade the physician to prescribe tests in order to avoid the charge of not doing everything possible; c) slow response time to the innovation mainly due to the difficulty of transmission and consolidation of knowledge. In fact, even decades can pass from the evidence of the usefulness or uselessness of a test to the concrete change in the prescriptive act [24-27].

This is a critical issue not only in the diffusion of new knowledge, but also in the use of tests that may be defined historical [28]. The knowledge is the intellectual tool of decision that manages not only the quality of the tests (usefulness of tests, strategies proposed by prescriptive guidelines, sensitivity, specificity, predictive value, technical features, legislation, and costs), but also and above all, the quantity of needed tests. The main critical issue that affects the knowledge lies in the fact that if the first edition of Merck's Manual of 1899 [29] listed 13 tests easily memorized, the tests available today are more than 500 and therefore over the human cognitive ability [30]. In this paper we present an innovative informatics solution, integrated to clinical processes, in order to change the clinical approach to laboratory tests and, that can be a tool for improving knowledge. The percentages of inappropriateness mentioned above, are the main indicators of lack of efficacy of the strategies used up to now (guidelines, protocols and flow charts, conventions, treaties, consensus conferences, agreements between colleagues). The same have also proved not to be adequate to affect permanently and quickly on behavioral change. We think crucial to apply structural instruments for the transmission of scientific information in order to allow: a) the continuing education in order to decrease the response time to innovation, b) the consolidation of the state of the art, c) the improvement of the transmission of knowledge, in order to overcome the criticality of clinical staff turnover, d) the homogeneity of behavior. We believe that such targets could be achieved through a strategic communication [31] using a Decision Support System (DSS), to promote virtuous behavior of physicians in the act of prescription. The indications provided were collected in a handbook for the correct prescription of both traditional and innovative tests and particularly in the fields of molecular biology, genomics, proteomics and epigenetics. The Health Information Technology (HIT) makes it possible to test solutions that will make the information accredited, updated and available on the point of care, so that prescribers can adopt the most appropriate, synthetic, and cost effective choices [32-36]. On the other hand, the literature shows that the use of a DSS improves significantly the performance of the physician and besides that, the attitude of General Practitioners (GPs) in respect of a DSS is good [37]. As regards the economic issue, the same in only a few studies has been exhaustively analyzed [38 - 41]. The way ahead is to adopt the indications generated by a consensus among peers and in agreement with the guidelines. Finally the idea has been to provide physicians with a list of indications updatable in real time and extensible progressively to most laboratory tests. The continuous updating through the information network would solve one of the main problems in the management of appropriateness. In fact, the judgment of appropriateness is often not a final choice, but is a developmental continuity linked to technological progress and scientific knowledge, and also to the cost/benefit. Connectivity should be the tool to define an explicit hierarchy and updated solutions, in which context the responsibility of prescribers might develop [42]. The aim of this paper is to illustrate the characteristics of a DSS and to present the results of two trials conducted in two Italian Health Care Authorities (Veneto Region). The objective of the trials was twofold: a) assessment of the technical feasibility of the software tool in terms of ease of use, while checking if the same software presented some sort of conflicts with the application programs of the General Practitioners (GPs); b) determining whether the use of the DSS could induce a change in prescribing behavior.

\section{Materials and Methods}

\subsection{The DSS}

The DSS, denomed Ermete, has been designed by one of the authors [43-44], and then applied to General Practitioners Electronic Medical Record (GP-EMR). The DSS interacts in real time with GP-EMR through a third software program linked to the first two, allowing a real time alert. In practice, the physician, in the action of prescription, when enters a test that the DSS has stated, a pop-up appears, where a summary of the suggestions established by Board are explained. Examples of prescribing indications listed on DSS are shown in Table 1. 
Table 1. Examples of prescribing indications listed on DSS.

\begin{tabular}{|c|c|}
\hline TEST & INDICATION \\
\hline Ammonium & $\begin{array}{l}\text { 1. Useful in the evaluation high-grade hepatic } \\
\text { insufficiency }\left(2^{\text {nd }} \text { level test). }\right.\end{array}$ \\
\hline Haptoglobin & $\begin{array}{l}\text { 1. Specific test for hemolytic anemia. Not suggested for } \\
\text { evaluation of inflammation. }\end{array}$ \\
\hline AST & $\begin{array}{l}\text { 1. Not recommended for screening and evaluation of } \\
\text { liver disease. }\end{array}$ \\
\hline Bence Jones & $\begin{array}{l}\text { 1. Suggested in patients with serum monoclonal } \\
\text { components and diagnosis of micro-molecular myeloma } \\
\left(2^{\text {nd }} \text { level test). }\right.\end{array}$ \\
\hline $\begin{array}{l}\text { C3 } \\
\text { Complement }\end{array}$ & $\begin{array}{l}\text { 1. Useful evaluation of the decrease in diseases by } \\
\text { increased consumption. Not suggested for evaluation of } \\
\text { inflammation. }\end{array}$ \\
\hline Ca 15.3 & $\begin{array}{l}\text { 1. Not suggested for the initial diagnosis of cancer. } \\
\text { Useful for the evaluation of extension, response to } \\
\text { treatment, early detection of } \\
\text { progression, monitoring of therapy for metastatic } \\
\text { disease. }\end{array}$ \\
\hline CA 125 & $\begin{array}{l}\text { 1. Useful to the differential diagnosis of benign disease, } \\
\text { restricted to adenocarcinoma of the ovary. Useful for the } \\
\text { evaluation of extension, response to treatment, early } \\
\text { detection of progression, monitoring therapy for } \\
\text { metastatic disease. } \\
\text { 2. Useful in the diagnosis of endometriosis }\end{array}$ \\
\hline OGTT & $\begin{array}{l}\text { 1. Useful in the evaluation of hyperglycemia in patients } \\
\text { with fasting plasma glucose higher than } 104 \text { and less } \\
\text { than } 125 \mathrm{mg} / \mathrm{dL} \text {. }\end{array}$ \\
\hline D Dimer & $\begin{array}{l}\text { 1. Useful to the exclusion of deep vein thrombosis and } \\
\text { pulmonary embolism. Recommended performing it in } \\
\text { Hospital. } \\
\text { 2. Useful in the diagnosis of DIC. Recommended } \\
\text { performing it in Hospital. }\end{array}$ \\
\hline $\begin{array}{l}\text { Protein } \\
\text { electrophoresis } \\
\text { electrophoresis }\end{array}$ & Ind monitoring of Monoclonal \\
\hline ENA & $\begin{array}{l}\text { 1. Suggested after the determination of ANA or if there } \\
\text { is a clinical suspicion of Systemic Autoimmune Disease } \\
\text { (SAID) }\left(2^{\text {nd }} \text { level test). }\right.\end{array}$ \\
\hline Ferritin & $\begin{array}{l}\text { 1. Useful in evaluating microcytic anemia. }\left(2^{\text {nd }} \text { level }\right. \\
\text { test) } \\
\text { 2. Useful in the evaluation of iron stores. }\left(2^{\text {nd }} l \text { level test }\right) \\
\text { 3. Useful in the diagnosis of hemochromatosis. }\left(2^{\text {nd }} l e v e l\right. \\
\text { test) }\end{array}$ \\
\hline fT3 & $\begin{array}{l}\text { 1. Not suggested for the initial evaluation and screening } \\
\text { of thyroid diseases (TSH useful). ( (2n level test) }\end{array}$ \\
\hline Homocysteine & $\begin{array}{l}\text { 1. Not suggested among the general population for the } \\
\text { evaluation of cardiovascular risk. }\end{array}$ \\
\hline
\end{tabular}

At this moment the prescriber may choose whether to join or not the suggestions. The software does not use a top-down logic, but the one of memory assistant, leaving the physician free will. In fact, the DSS requires four reasons for nonadherence to the indication proposed. The reasons have been designed so as to be always the same, regardless of the selected test (table 2).

Table 2. Reasons for non-adherence.

Clinical situation not provided for indication.
Specialist prescription.
Disagreement on the indication.
Other reasons.

The only condition subsistent is to motivate the choice, indicating one of four different reasons. The acceptance of indication occurs by a click that automatically inserts the test in the recipe. The choices of prescription are logged by generating an Excel file that records the number of times the test was prescribed according to the proposed indication and how many times was chosen the non-adherence and why. The tests are available with two ways: a) search for a single test; b) search into pathology folders, represented by logical groups related to certain diseases (liver, thyroid, check-ups, etc.) or in subfolders (e.g. weeks of gestation). The pathology folder offers the advantage of being able to display the test useful within a given pathology scope and in the case of a test with more indications, presenting only the indication relevant to the scope of the folder (Table 3 ).

Example is represented by the test Prothrombin Time in Table 3.

Table 3. Example of the test Prothrombin Time.

The single test has three indications:
Useful in assessing the risk of bleeding or a hemorrhagic event.
Useful in monitoring oral anticoagulant therapy
Evaluation of hepatic insufficiency and malabsorption.
The same test prompted in the folder "liver disease" shows only indication
3: Possible use in the evaluation of liver disease and malabsorption.

Moreover, the references used to build up the indication can be displayed for each test. The program is customizable so that it can display information such as the place of execution, information for patient (diet, exercise, posture, etc.), collection methodology (urine twenty-four hour, urinary cytology, etc.), mandatory indications (niche tests, pregnancy, etc.), number of tests that may be prescribed in each recipe.

\subsection{Design of DSS}

The idea comes from a paper by Karl Raimund Popper in which the epistemologist wondered: "how to act in circumstances where the available information are incomplete" [45]. The logic of construction of the DSS and of indications of prescribing departs from the studies of cognitive science [46-50]. According to them the decision with little time available, both in the relational life (economic investments, rentals, purchase of goods) and professional (prescriptive act) is entrusted mainly on intuition or, more simply on the good sense, to guide us through countless shortcuts to solve rapidly complex problems, when information are lacking. As exemplification it might be used as hyperbolic image, the one of the hunter: which hunter, facing a wild lion, with pen and paper would calculate the trajectory of the bullet? No one would, having to take the action more possible and faster. This is the mindset that we daily use and that is unconsciously the main source of our mistakes. The example shown may help to understand the building logic of the DSS, in fact the physician too, in the prescriptive act, is facing a "wild lion", represented by the patient with his medical needs and anxieties, by the limited time available, by bureaucracy, by ranks of the patients out door, by difficulties in finding information hic et nunc (here and now), by the inadequacy of memory and reasoning biases 
[51]. The DSS has been designed on Theories of Bounded Rationality of Herbert Simon (Nobel Prize in Economics, 1978 ) in order to provide the physician with the minimum number of elements for deciding, that is to say the rescribing indications" were able to restrict the information needed for right choice tests. The prescribing indications are the aid to the physician in the practice, synthesizing and making available an, otherwise, not manageable number of information and guiding the same physician in the context of the wide range of possibilities, in order to find the main road in the intricate Babel of scientific knowledge, regulations and economic contingency. Indeed, no clinician can fully know and correctly use the array of tests available. It 's obvious that the indications are not built to exhaust all existing diagnostic possibilities or to conclude the cognitive process, or crystallize the complexity in canned recipes within a schema, but they should have the function of establishing a backup point, updated in real time over the network, where the evidence is given by the revision index. This is the reason why a test can be accepted in disagreement with the proposed indication. This means providing a wide range of freedom and autonomy. Therefore, the indication acts as an advice, as a guide on the route to be taken and also as a tool for governance of knowledge in its original etymological meaning. The only prerequisite required by the DSS is the reason of choice, free from sanctioning issues (ticket not refundable, inspections etc.)

\subsection{The Board}

A scientific board has been set up in order to build the prescribing indications and ensure scientific authority, continuous updating and sharing with GPs. The board in both trials consisted of a group of permanent members, formed by the Inventor of the software, by Directors of Laboratory Medicine, Hospital General Medicine, Health and Social Care and by a delegation of the GPs. Whenever it has been necessary to have specialized information (e.g. nephrology, gynecology, hepatology, rheumatology, etc.), the Board involved professionals, accredited in the specific discipline. The six rules on which the Board based its building the "indications" are shown in Table 4. The reference sources in the building the indications have been intentionally limited, due to the fact that at that stage it was matter of priority checking the feasibility and efficacy of the tool. For this purpose as references the latest edition of Harrison's [52], some guidelines of Scientific Societies and the Clinical experience of the participants to the Board were taken. So, the "indications" had purpose to be the compendium of the observation of the events that clinicians every day face and attempt to turn into a permanent features, from which obtaining defined rules and verbal formulations. The verbal formulation, as known in linguistics, is all the more effective the higher its shortness, clarity and density of statement [53]. The final choice was that to adopt short statements in which focusing complex processes and a "method" of choice of performances, the latter divided into levels, according with nosology and costs (table 5).
Principles for building rules in Table 4 e Table 5.

Table 4. Principles for building rules.

Tending toward a process of synthesis of scientific knowledge,

1 reporting the essential specialized knowledge through short, unambiguous and easy to understand sentences.

Building information tools useful in the prescribing at the precise time

2 of need, that is to say "in front of the patient," when the physician has limited time and trouble to consult scientific sources.

Highlighting the elements needed during the prescription by removing the information useful for the only interpretation of results. e.g. ACE (Angiotensin Converting Enzyme): the DSS submits only the indication "Useful for diagnosis and monitoring of sarcoidosis."

3 There are not knowingly information useful for the interpretation of a result out of the reference values, but that does not justify a prescription for a diagnosis of diabetes, primary biliary cirrhosis, myeloma, chronic lung disease, hyperthyroidism, amyloidosis, situations in which the literature reports this enzyme increasing. Identifying right application area for some laboratory tests and, defining consequently the clinical situations in which their use is a

4 priori inappropriate.

e.g. Markers of Cancer: it is possible to establish for many of them the inappropriate prescription for diagnostic purposes.

Even if it is not possible to define a priori the sure inappropriateness for other tests, it is possible to identify the rational limits of use. It

will then be possible to suggest the right clinical environment of some tests and to exclude instead others.

e.g. AST: it is not rational to propose its prescription for suspicion of early liver disease.

Establishing priority levels of prescription for some tests $\left(1^{\text {st }}\right.$ and $2^{\text {nd }}$ level tests).

e.g. Ammonium: it is a $2^{\text {nd }}$ level test, which is useful in the evaluation of stated high-grade hepatic insufficiency.

Table 5. Example of building rules.

\begin{tabular}{ll}
\hline Rule & $\begin{array}{l}\text { Useful in evaluating macrocytic } \\
\text { anemia. } 2^{\text {nd }} \text { level test }\end{array}$ \\
\hline FOLIC ACID & The short sentence is the following: \\
before prescribing the determination \\
of folic acid it is appropriate to have \\
the evidence of macrocytic anemia, \\
that is to say, a complete blood count \\
with hemoglobin less than the \\
reference values and increased MCV.
\end{tabular}

For the purposes of the trial, indications for only 110 tests and only 10 Pathology folders have intentionally been formulated and structured.

\subsection{Detailed Rules of Trial}

On the basis of the above solutions, two trials were carried out using the DSS, the first, lasted six months, at Local Health Care Authority of Rovigo in 2008, involving 23 voluntary GPs, the second, lasted seven months, at the Local Health Authority of Mirano in 2010 involving all 196 local GPs. In both trials, the data of prescriptions processed with the use of the DSS were compared with the data of prescriptions dispensed by the same physicians, in the same months of the previous year. In the trial of Rovigo it was used as control group, data (provided by the Management Control) from all other GPs who did not use DSS. In the trial of Mirano, having all GPs participated in the trial, it was used as a control group data relating to 671 GPs of Veneto Region 
(non-user DSS), extrapolating the data from management programs used by GPs. The training was made up of a learning event on themes of appropriateness and on explanation of the logic of DSS. The operating characteristics of the software were provided when the DSS was installed, by means of a synthetic and specific operating procedure.

\section{Results}

\subsection{Trial of Rovigo}

Between years 2007 and 2008, the results showed a decrease by $37.2 \%$ of the tests (DSS listed) prescribed according to the proposed indication and a decrease by $13.5 \%$ of all prescribed tests, including those without indications (Table 6).

Results relating to the only tests with DSS VS without DSS in table 6

Table 6. Results relating to the only tests with DSS VS without DSS.

\begin{tabular}{llll}
\hline Without DSS - year 2007 & DSS - year 2008 & $\begin{array}{l}\text { Nrs } \\
\text { decWithrease }\end{array}$ & $\begin{array}{l}\text { \% } \\
\text { decrease }\end{array}$ \\
\hline $\begin{array}{l}29.703 \\
\begin{array}{l}\text { Results relating to all tests } \\
\text { with and without DSS }\end{array}\end{array}$ & 18.660 & 11.043 & $37.2 \%$ \\
Without DSS - year 2007 & With DSS - year & Nrs decrease & $\begin{array}{l}\% \\
\text { decrease } \\
118.848\end{array}$ \\
\hline
\end{tabular}

In the control group of GPs without DSS, the tests were increased by $4 \%$. Significant changes in the prescription of some single test were also measured (Table 7).

Trial of Rovigo with 23 GPs: changes of some tests without DSS (2007) and with DSS (2008) in table 7.

Table 7. Results relating to the only tests with DSS VS without DSS.

\begin{tabular}{lllll}
\hline TEST & Year 2007 & Year 2008 & $\begin{array}{l}\text { Nrs } \\
\text { Change }\end{array}$ & \% Change \\
\hline Urea & 2510 & 1010 & 1500 & $-60 \%$ \\
AST & 4601 & 1965 & 2636 & $-57 \%$ \\
Lipase & 101 & 52 & 49 & $-49 \%$ \\
fT3 & 991 & 613 & 378 & $-38 \%$ \\
Fibrinogen & 391 & 222 & 168 & $-43 \%$ \\
Protein & 1593 & 1078 & 515 & $-32 \%$ \\
Electrophoresis & & 127 & 46 & $-27 \%$ \\
CA 125 & 173 & 696 & 312 & $-31 \%$ \\
ALP & 1008 & 155 & 69 & $-31 \%$ \\
Antithrombin & 224 & 959 & 410 & $-30 \%$ \\
Iron & 1369 & 673 & 271 & $-29 \%$ \\
Ferritin & 944 & 215 & 57 & $-21 \%$ \\
CA 19.9 & 272 & 1358 & 362 & $-21 \%$ \\
PSA & 1720 & 1340 & 344 & $-20 \%$ \\
fT4 & 1684 & 1211 & 308 & $-20 \%$ \\
Direct Bilirubin & 1519 & &
\end{tabular}

The medical experimenters, interviewed by telephone, judged DSS tool useful, practical and applicable in daily work.

\subsection{Trial of Mirano}

Since DSS was provided to GPs without any specific training on program, it was not utilized on an ongoing basis, as highlighted by evaluation of the results and by interviews with Prescribers (for example, during leave or sickness when Prescribers were replaced by colleagues who did not know the use of DSS). When the Prescribers continuously used the DSS, the test number decreased by $26.1 \%$ (Table 8 ). Significant changes in prescription of some single test were also measured (Table 9). Otherwise, in control group (DSS non-usrers) the tests increased by $4.1 \%$.

Results relating to the only tests with DSS VS without DSS in table 8

Table 8. Results relating to the only tests with DSS VS without DSS.

\begin{tabular}{llll}
\hline $\begin{array}{l}\text { Without DSS - year } \\
\mathbf{2 0 0 7}\end{array}$ & $\begin{array}{l}\text { With DSS - year } \\
\mathbf{2 0 0 8}\end{array}$ & $\begin{array}{l}\text { NRS } \\
\text { decrease }\end{array}$ & $\begin{array}{l}\text { \% } \\
\text { decrease }\end{array}$ \\
\hline 225.080 & 166.440 & 58.640 & $26,1 \%$ \\
\hline
\end{tabular}

Trial of Mirano with 196 GPs: changes of some tests without DSS (2009) and with DSS (2010) in Table 9.

Table 9. Trial of Mirano with 196 GPs: changes of some tests without DSS (2009) and with DSS (2010).

\begin{tabular}{lllll}
\hline TEST & $\begin{array}{l}\text { Year } \\
\mathbf{2 0 0 9}\end{array}$ & $\begin{array}{l}\text { Year } \\
\mathbf{2 0 1 0}\end{array}$ & $\begin{array}{l}\text { Nrs } \\
\text { Change }\end{array}$ & $\begin{array}{l}\text { \% } \\
\text { Change }\end{array}$ \\
\hline Fructosemia & 237 & 57 & 180 & $-76 \%$ \\
5HT & 40 & 19 & 21 & $-52 \%$ \\
Ca72.4 & 20 & 12 & 8 & $-40 \%$ \\
AST & 81.455 & 58.725 & 22.730 & $-28 \%$ \\
fT3 & 16.700 & 12.520 & 4.180 & $-25 \%$ \\
D-dimer & 134 & 107 & 27 & $-20,00 \%$ \\
OGTT & 155 & 125 & 30 & $-19 \%$ \\
C-protein & 939 & 783 & 156 & $-17 \%$ \\
CYFRA 21.1 & 117 & 99 & 18 & $-15 \%$ \\
Pseudocholinesterase & 1.042 & 894 & 148 & $-14 \%$ \\
ALP & 17.407 & 15.382 & 2.025 & $-12 \%$ \\
Reticulocyte test & 908 & 796 & 112 & $-12 \%$ \\
Urea & 46.375 & 41.059 & 5.316 & $-11 \%$ \\
Direct Bilirubin & 16.098 & 14.614 & 1.484 & $-9 \%$ \\
PSA & 6.161 & 5.666 & 495 & $-8 \%$ \\
\hline
\end{tabular}

During both trials, technical critical issues related to Information Technology, between DSS and GP- EMR did not occur. These features were of course key elements to assess the technical feasibility of applying software.

\section{Discussion}

It is mandatory in order to comment on results and assess the potentialities of software, to recall that in the experimental phase the indications knowingly regarded some of the more than 500 tests available, and that 10 pathology folders had only been structured. The overall decrease by $37.2 \%$ obtained in Rovigo may be in our opinion considered a good result, aligning this datum with the ones reported in the literature. But it is also true that a careful assessment of appropriateness would require during the trial the knowledge of the clinical questions that led the prescriptions, as well as knowing the outcome. In spite of these limitations, it seems reasonable to believe that the results shown could be considered a positive indicator of appropriateness. On the other hand, the DSS is chiefly a system of knowledge management, representing the appropriateness, the 
epiphenomenon of its application. In addition to the datum of the overall decrease by $13.5 \%$ of prescribed tests can be positively interpreted as meaning that the use of DSS has probably changed the prescribing behavior, even for tests for which indications had not been provided. This is a present hypothesis, but the increase by $4 \%$ of prescriptions in the control group that did not use DSS, leads us to consider it likely. On the other hand Prescribers that joined on a voluntary basis to the research committed themselves to continuously utilize the DSS, prefiguring the possible results achievable by the use of the software in wide population of highly motivated Prescribers. The overall decrease of $26.1 \%$ in Mirano is a positive result considering the increase in the prescription of 4.1 in the control group, but probably affected by the use of DSS on non-voluntary basis, and by the lack of a structured training. The results achieved may be ascribed to the synthesis of several factors. The instant faculty of DSS to access the GP-EMR without needing to change or enter other applications played a crucial role. A further factor of compliance was the graphical intuitive feature of interface, as also pointed out by the experimenters. The probably most effective property was the freedom of prescription that DSS allows the physician. The act of freedom is particularly expressed in the sentence "non-adherence for other reasons", allowing the physician a choice of opportunities towards the patient. Opportunity is a different situation than appropriateness, regarding the first the world of values rather the one of knowledge and expertise. For example, prescriptions pressed by the patient and relatives can be justified on the basis of a broader assessment such as the psychological wellness of the person or the family, but even the impossibility of the same patient to submit himself to tests at two different times, as the logic of DSS might propose (e.g. first and second level tests). Finally, a crucial element has been the recognition by Prescribers of the authoritativeness of Board members, whom a relationship between peers has been established, with so that a circular and bi-directional communication overcame, and that the same allowed the transmission of knowledge among organizational nodes (Prescribers, Local Health Authority, and Laboratory Medicine) [54]. A weak point in the building of DSS should be the simplification of information. Shortness and simplicity of the sentences has two precise reasons. Shortness is useful to support the action of the prescribing physician, but also to call to mind concepts that should already be baggage of his knowledge. On the other hand, simplicity is likewise useful to transmit to physician, by means of a phrase "ad hoc" (for this), information that instantly recalls the complexity of the clinical picture. A point of strength, instead, should be the logic of the DSS when, in addition to limiting the use of a test (for example the fT3, Table 1), proposes alternative performance (e.g. TSH), but also when, in case of cultural gap, the same DSS proposes bibliographic references, offering physicians prompt to deepen knowledge, that may be also later performed. In this case an undeniable authoritativeness of the Board is needed. With regard to defensive medicine, we believe that the indications provided by DSS in association with risk management strategies, do not tout court safeguard the forensic immunity, but may represent a guarantee of good medical practice, as they contain the summary of medical knowledge, and of ethic behavior [55-58]. In this case too, an undeniable authoritativeness of the Board is needed. Even if it has not been possible to take out the share of tests induced by defensive behavior, the results obtained utilizing the DSS may be assessed as a contribution in decreasing number of tests prescribed for the benefit of physician and not of patient. Last but not least, the financial side. Appropriateness is one of the main tools for spending review, as well as for application of principles of morals and justice, according to which the limited financial resources should be devolved to useful health benefits. In this regard, the trials show the potential for governance of the prescription without resorting political and administrative actions (ticket, taxes, fixing a quota on reservations, etc.) that could lead to restrictions and inequalities induced by a spending review not guided by scientific criteria [59-60]. On the other hand, medical doctors have to ensure that computer solutions planned for management of knowledge are not misused as a means of control and inspection or restriction of prescriptive freedom. The DSS, in this regard, has been designed as a solution managed exclusively by physicians so that no one could consider it a "Deus ex machina". In fact, DSS has to work close to physicians as a tool modifiable and adaptable to new needs of knowledge, as well as a dynamic machine continuously rebuildable.

\section{Conclusion}

On the basis of the foregoing, we believe that DSS Ermete might be a tool able to manage demand for laboratory tests, inducing a change in prescribing behavior, allowing, at the same time, the physician full decisional freedom and autonomy. By improving the appropriateness it might be possible to handle the challenges in the future, offering to users prescriptions proper to their clinical needs, updated and consistent with scientific progress, as well as economically viable.

\section{References}

[1] Zimmern RL. Testing challenger: evaluation of novel diagnostics and molecular biomarkers. Clin Med 2009; 9: 6873.

[2] Lundberg GD. The need for an outcomes research agenda for clinical laboratory testing. JAMA 1998; 280: 565-6.

[3] Forsman RW. Why is the laboratory an afterthought for managed care organization? Clin Chem 1996; 42: 813- 6 .

[4] ARSS Regione Veneto. Ricognizione del sistema di produzione di prestazioni di Medicina di Laboratorio e Microbiologia del Servizio Socio Sanitario Veneto. 2007.

[5] Plebani M. Exploring the iceberg of errors in laboratory medicine. Clin Chim Alta 2009; 404: 6-23. 
[6] Report of the Second Phase of the Review of NHS Pathology Services in England. Chaired by Lord Carter of Coles. Dec 2008.

http://www.dh.gov.uk/en/Publicationsandstatistics/Publication s/PublicationsPolicyAnd Guidance/DH_091985 (accessed March 2016).

[7] Fryer AA, Hanna FW. Managing demand for pathology tests: financial imperative of duty of care? Ann Clin Biochem 2009; 46: 435-7.

[8] Janssens PMW. Managing the demand for laboratory testing: Options and opportunities. Clin Chim Acta 2010; 411: 1596602.

[9] Alonso-Cerezo MC, Martín JS, García Montes MA, et al. Appropriate utilization of clinical laboratory tests. Clin Chem Lab Med 2009;47:1461-5.

[10] National Coalition of Public Pathology. Encouraging Quality Pathology Orderingin Australia's Public Hospitals-Final Report. Feb 2012. http://www.ncopp.org.au/ UserFiles/file/NCOPP\%20QUPP\%20Project\%20Final\%20Re port\%20(web).pdf (accessed March 2016).

[11] Smellie WSA. Demand management and test request rationalization. Ann Clin Biochem 2012; 49: 323-36.

[12] Hauser RG, Shirts BH. Do we now know what inappropriate laboratory utilization is? An expanded systematic review of laboratory clinical audits. Am J Clin Pathol 2014; 141: 774783.

[13] Hallworth MJ, Epner PL, Ebert C et al. Current evidence and future perspectives on the effective practice of Patient-Centered Laboratory Medicine. Clin Chem 2015; 61: 589-599.

[14] Miyakis S, Karamanof G, Liontos M, et al. Factors contributing to inappropriate ordering of tests in an academic medical department and the effect of an educational feedback strategy. Postgrad Med J 2006; 82: 823-9.

[15] Hampton JR, Harrison MJ, Mitchell JR, et al. Relative contributions of history-taking, physical examination, and laboratory investigation to diagnosis and management of medical outpatients. Br Med J 1975; 2: 486-9.

[16] Sandler G. Do emergency tests help in the management of acute medical admissions? Br Med J (Clin Res Ed) 1984; 289: 973-7.

[17] $\mathrm{Fu} \mathrm{C}$, Ji L, Wang W, et al Frequency of HbA1c monitoring was inversely associated with glycemic control of patients with type 2 diabetes mellitus. J Endocrinol Invest 2012; 35: 269-73.

[18] Driskell OJ, Holland D, Hanna FW, et al. Inappropriate requesting of $\mathrm{HbAlc}$ is widespread: Assessment of prevalence, impact of national guidance and practice-to-practice variability. Clin Chem 2012; 58: 906-15.

[19] Sandler G. Costs of unnecessary tests. Br Med J 1979; 2: 21-4

[20] Zhi M, Ding EL, Theisen-Toupal J et al. The landscape of inappropriate laboratory testing: a 15-year meta-analysis. PLoS ONE 2013; 8: e78962.

[21] Cappelletti P. Praticare l' appropriatezza in Medicina di Laboratorio. Un aggiornamento. Riv Ital Med Lab 2016; 12: 65-69.

[22] van Walraven C., Naylor D. Do we know what inappropriate laboratory utilization is? JAMA 1998; 280: 550- 58.

[23] Castelli-Boada JM, Castells-Oliveres X. Appropriateness of physicians' requests of laboratoty examinations in Primary Health Care: an over- and under- utilization study. Clin Chem Lab Med 1999; 37: 65-9.

[24] Plebani M, Laposata M. Translational research involving new biomarkers of disease: a leading role for pathologists. Am J Clin Pathol 2006; 26: 169-71.

[25] Camerotto A, Natali G, Carmignoto F. Aspartato e Alanina Transaminasi: alcune considerazioni su due esami della met?del XX?secolo: la fisiopatologia, il metodo ed il razionale della richiesta. Biochim Clin 2006; 30: 224-32.

[26] Camerotto A, Di Liddo R, Carmignoto F. Il tempo di risposta all'innovazione: un indicatore di efficacia nell'applicazione delle linee guida, procedure e tecnologie innovative. Riv Ital Med Lab 2006; 2: 206-14.

[27] Lewandrowski K. Managing utilization of new diagnostic tests. Clin Leadersh Manag Rev 2003; 17: 318-24.

[28] Wu AH, Lewandrowski K, Gronowski AM, et al. Antiquated tests within the clinical pathology laboratory. Am J Manag Care 2010; 16: e220-7.

[29] Merk's Manual of the materia medica. New York: Merk'\& Co; 1899.

[30] Camerotto A, Formenton F, Ramazzina E. L'inappropriatezza nella richiesta di test di laboratorio per difetto di conoscenza. Errore individuale o errore di sistema? Biochim Clin 2007; 31: 209-15.

[31] Schutz A. Saggi Sociologici. Torino: UTET; 1979.

[32] Fryer AA, Smellie WSA. Managing demand for laboratory tests: a laboratory toolkit.

http://jcp.bmjjournals.com/content/early/2012/09/25/jclinpath2011-200524.full.(accessed march 2016).

[33] Brice CP. Evidence-based Laboratory Medicine: supporting decision-making. Clin Chem 2000; 46: 1041-50.

[34] van Wijk MA, van der Lei J, Mosseveld M, et al. Assessment of decision support for blood test ordering in primary care. a randomized trial., Ann Intern Med. 2001 Feb 20; 134 (4): 274-81.

[35] Camerotto A, Pozzato A., Truppo V, et al. Il oftware? GOELM come innovativa modalit?di gestione della conoscenza e della prescrizione degli esami di laboratorio: l'esperienza di due Unit?Sociosanitarie Locali. Biochim Clin 2012; 36: 98-106.

[36] Seidling HM, Phansalkar S, Seger DL, et al. Factor influencing alert acceptance: a novel approach for predicting the succees of clinical decision support. J Am Med Inform Assoc 2011. http/www.ncbi.nlm.nih.gov/pmc/articles/PMC3128393/ (accessed march 2016).

[37] Heselmans A, Aertgeerts B, Donceel P, et all, Family Physicians' Perceptions and Use of Electronic Clinical Decision Support During the First Year of Implementation. J Med Syst, Dec; 36(6): 3677-84.

[38] Main C, Moxham T, Wyatt JC, et al, Computerised decision support systems in order communication for diagnostic, screening or monitoring test ordering: systematic reviews of the effects and cost-effectiveness of systems. Health Technology Assessment 2010; Vol. 14: No. 48. 
[39] Ohno-Machabo Lucila. Cost- effectiveness of informatics and health IT: impact on finances and quality of care. J. Am. Med Inform Assoc May 2012 Vol 19 n. 3.

[40] van Wijk MA, van der Lei J, Mosseveld M, et al. Assessment of decision support for blood test ordering in primary care. a randomized trial. Ann Intern Med. 2001 Feb 20; 134(4): 274 81 .

[41] Poley MJ, Edelenbos KI, Mosseveld M. Cost Consequences of Implementing an Electronic Decision Support System for Ordering Laboratory Tests in Primary Care: Evidence from a Controlled Prospective Study in The Netherlands. Clinical Chemistry 2007; 53: 2213-9.

[42] Mirvis DM, Chang CF. Managed care, managing uncertainty. Arch Int Med 1997; 157: 385-8.

[43] Camerotto A, De Toni S, Carmignoto F. L'adozione di note di prescrivibilit? per i test di laboratorio pu?essere uno strumento di migliore appropriatezza? Mecosan management ed economia sanitaria (Uni Bocconi, Milano) 2004; 51: 71-76.

[44] Camerotto A, Truppo V, Bedendo S, et al. The named Hermes ICT design of Veneto Region for knowledge management in Laboratory Medicine. Riv Ital Lab Med 2014; 10: 125-35.

[45] Popper KR Conjectures and refutations the growth of scientific knowledge. London: Routledge; 1963.

[46] Bianchi A, Di Giovanni P. Psicologia cognitiva. Milano: Mondatori; 2000.

[47] Piattelli Palmarini M. Illusioni di sapere. Che cosa si nasconde dietro i nostri errori. Milano: Mondatori; 1999.

[48] Bara BG. Scienza cognitiva. Un approccio evolutivo alla simulazione della mente. Torino: Bollati Boringhieri; 1990.
[49] Delvecchio G. Decisione ed errore in medicina. Torino: Centro Scientifico Editore; 2005. Bollati Boringhieri; 1990.

[50] Taleb NN, The Black Swan. The impact of the highly improbable. Completed with the second edition including a long essay "On Robustness and Fragility". New York: Random House and Penguin; 2010.

[51] Gewin V. Surreptitious sleep states uncovered. http://nature.com/news/2011/110427/full/news.2011.259.htlm / (accessed march 2016).

[52] Kasper DL, Braunwald E, Fauci AS, et al. Harrison Principi di Medicina Interna XVI?ed. Milano: McGraw-Hill; 2005.

[53] Lombardo Vallauri E. La linguistica. Bologna: Il Mulino; 2007.

[54] De Toni A, Pomello L. Prede o ragni. Torino: UTET; 2005.

[55] Puccini C. Istituzioni di Medicina Legale. Milano: Casa Editrice Ambrosiana; 1984.

[56] Frati P. Responsabilit?professionale. Guida all'esercizio professionale per i medici chirurghi e gli odontoiatri. Torino: Edizioni Medico Scientifiche; 2000. p. 331-5.

[57] Qaseem A, Forland F, Macbeth F et al. Guidelines International network: verso standard internazionali per la produzione di linee guida. www. Evidence.it Ottobre 2012.

[58] Smellie WSA, Finnigan DI, Wilson D et al. Methodology for constructing guidance. J Clin Pathol 2005; 58: 249-53.

[59] Bottari C, Roversi M. La tutela della salute tra garanzie degli utenti ed esigenze di bilancio. Santarcangelo di Romagna; Maggioli: 2012.

[60] Illich Ivan. Medical Nemesis. London; Calder \& Boyars: 1974. 